\title{
Optical Electrophysiology: Femtosecond Laser Facilitated Electrophysiological Measurements from Single Cells
}

\author{
Ali Aytaç Seymen ${ }^{1,2,3}$, Erol Özgür ${ }^{1,2}$, Bülend Ortaç ${ }^{1,2}$ \\ 1. UNAM-Institute of Materials Science and Nanotechnology, Bilkent University, 06800 Ankara, Turkey \\ 2. E-A Teknoloji Ltd. Sti., Cyberpark, 06800 Ankara, Turkey \\ 3. Dept. of Physiology, Faculty of Medicine, Erciyes University, 38039 Kayseri, Turkey
}

One of the indispensable tools of electrophysiology is patch-clamp recording, which enables direct observation of ionic transport through cellular membranes. It is an invaluable research tool, providing experimental information related to cellular electrical metabolism, as well as various pathological conditions. While the inventors of patchclamp recording subsequently became Nobel laurates [1], still it can be considered as one of the most complicated experimental setups, due to the difficulty in puncturing cells using capillary microelectrodes with extreme precision. The throughput of the measurement is also considerably low. Thus, automatized planar patch-clamp systems depending on automatic suction of cells using special chips have emerged, considerably increasing the throughput of electrophysiological measurements for about a decade [2]. However, they are generally restricted to be used only with cultured cells, while they have a poor applicability when isolated cells are considered. Real-time observation of the cells for quality assessment, in terms of the measurement, is also not possible.

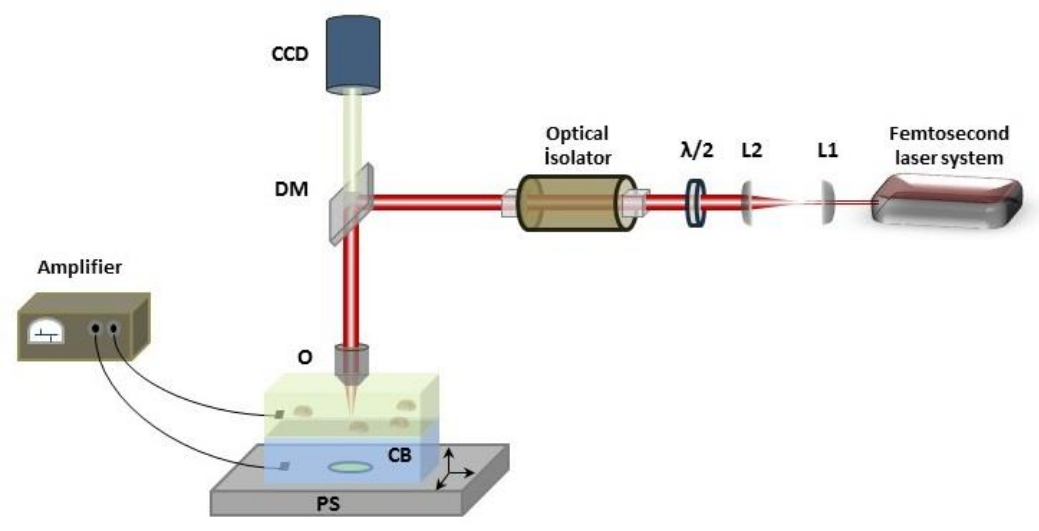

\begin{abstract}
Fig. 1 The experimental setup for laser assisted electrophysiology measurements. Femtosecond laser pulses are used to form a hole in the polymer film, and to open the cell membrane without harming the whole cell. The two electrodes measure the electrical activity in both the cellular solution (top) and the electrode solution. This all-optical configuration enables measurement of electrical conductance through the cell membrane without use of conventional micropipettes. The setup differs from the planar patch-clamp system with the ability to choose the cell that the experiment would be performed.
\end{abstract}

Here, a novel laser assisted method for performing cellular electrophysiological measurements is suggested and experimentally demonstrated. Femtosecond lasers have previously been used to form nano-sized pores on cell membranes [3], and their effect on membrane electrical polarization was also investigated [4]; however, this study is their very first utilization in electrophysiology. In this study, femtosecond laser pulses, coupled to an optical microscope, are used to first form a micrometer sized pore on a thin polymer membrane separating two electrodes. Afterwards, the nearby cell is sucked on the pore, and a small hole on this cell is formed again with the femtosecond laser, revealing the membrane over the pocket for electrophysiological recording. This method could be utilized to increase the throughput of electrophysiological measurements substantially, while providing ultimate control to the researcher over the experiment, which is non-existent in planar systems.

\section{References}

[1] E. Neher and B. Sakmann, "Single Channel Currents Recorded from Membrane of Denervated Frog Muscle Fibres," Nature, 260, 799 (1976).

[2] N. Fertig, R. H. Blick, J. C. Behrends, "Whole Cell Patch Clamp Recording Performed on a Planar Glass Chip," Biophys. J., 82, 3056 (2002).

[3] D. Stevenson, B. Agate, X. Tsampoula, P. Fischer, C. T. A. Brown1, W. Sibbett, A. Riches, F. Gunn-Moore, and K. Dholakia, "Femtosecond Optical Transfection of Cells: Viability and Efficiency," Opt. Express., 14, 7125 (2006).

[1] J. Ando, N. I. Smith, K. Fujita, Satoshi Kawata, "Photogeneration of Membrane Potential Hyperpolarization and Depolarization in NonExcitable Cells," Eur Biophys J., 38, 255 (2009). 